\title{
Computational fluid dynamic simulations of a cavopulmonary assist device for failing Fontan circulation
}

W. C. Patrick Lin, MASc, ${ }^{a}$ Matthew G. Doyle, PhD, ${ }^{\mathrm{a}, \mathrm{b}} \mathrm{S}$. Lucy Roche, MB, ChB, ${ }^{\mathrm{c}}$ Osami Honjo, MD, PhD, ${ }^{\mathrm{d}}$

Thomas L. Forbes, MD, ${ }^{b}$ and Cristina H. Amon, $\mathrm{ScD}^{\mathrm{a}, \mathrm{e}}$

\section{ABSTRACT}

Objectives: Adult patients who have undergone the Fontan procedure are highly vulnerable to gradual, progressive circulatory failure, and options to reverse this situation are few. A cavopulmonary assist device could decongest the venous and lymphatic systems, overcome elevated pulmonary vascular resistance, increase cardiac output, and support some of these patients to heart transplant. This study characterizes the performance and challenges of a novel multilumen cannula coupled to an external blood pump proposed as a potential Fontan cavopulmonary assist strategy.

Methods: Computational fluid dynamic simulations were conducted for 3 extracardiac Fontan geometries consisting of 1 idealized model and 2 patient-specific models. A range of physiologic flow rates and pump assist levels were simulated to calculate the pressure gain provided by the multilumen cannula. Hemolysis index was estimated for the idealized model with Lagrangian particle tracking and 2 variations of the power-law. Wall shear stresses were also examined.

Results: Pressure gains up to 4 and $9 \mathrm{~mm} \mathrm{Hg}$ were achieved for the idealized and patient-specific models, respectively. Pressure gains increased with both higher cardiac output and larger pump intake through the external pump. Flowweighted hemolysis show hemoglobin damage levels to be several times lower than the $2 \%$ threshold at the highest pump intake flow cases. Wall shear stress predictions depict elevated areas in the pulmonary vessels and regions of the cannula device.

Conclusions: The cannula tested in this study shows promise as a percutaneous option to bridge support in some patients with a failing extracardiac Fontan. Limitations identified will be addressed in future design iterations and in ongoing experimental tests. (J Thorac Cardiovasc Surg 2019;158:1424-33)

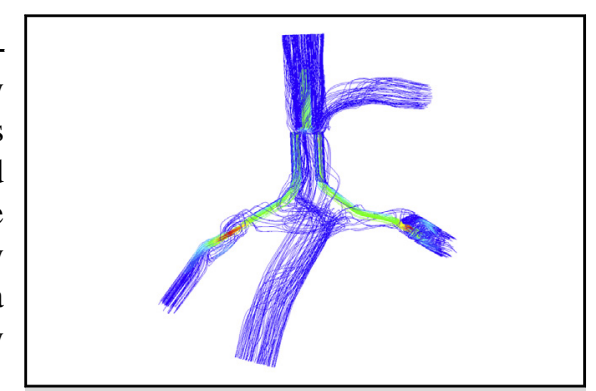

Novel multilumen cannula for bridging patients with a failing Fontan to transplant.

\section{Central Message}

Computational simulations of a novel cavopulmonary assist strategy show potential as a temporary option for treating patients with a failing extracardiac Fontan.

\section{Perspective}

Challenges with providing cavopulmonary assist in the TCPC for failing Fontan circulations lead to limited options for temporary and long-term treatments. Computational simulations show that a percutaneously inserted multilumen cannula coupled to a commercially available blood pump could provide mechanical circulatory support for certain patients who have undergone the Fontan.

See Commentaries on pages 1434 and 1436.
From the ${ }^{\mathrm{a}}$ Department of Mechanical and Industrial Engineering; ${ }^{\mathrm{b}}$ Division of Vascular Surgery, Department of Surgery, and ${ }^{\mathrm{c}}$ Division of Cardiology, Department of Medicine, Peter Munk Cardiac Centre, University Health Network; ${ }^{\mathrm{d} D i v i-}$ sion of Cardiovascular Surgery, Department of Surgery, Labatt Family Heart Centre, The Hospital for Sick Children; and ${ }^{\mathrm{e}}$ Institute of Biomaterials and Biomedical Engineering, University of Toronto, Toronto, Ontario, Canada.

Funded by the EMHSeed Grant from Faculties of Applied Science \& Engineering and Medicine at the University of Toronto, NSERC Discovery Grant, Ted Rogers Centre for Heart Research Innovation Fund, and Saving Tiny Hearts Society Grant.

Received for publication Aug 9, 2018; revisions received Jan 13, 2019; accepted for publication March 2, 2019; available ahead of print April 17, 2019.

Address for reprints: Matthew G. Doyle, PhD, 5 King's College Rd, Toronto, ON M5S 3G8 Canada (E-mail: mg.doyle@utoronto.ca).

$0022-5223 / \$ 36.00$

Copyright (c) 2019 by The American Association for Thoracic Surgery

https://doi.org/10.1016/j.jtcvs.2019.03.008
Although creation of a Fontan circulation allows the majority of patients born with single ventricle congenital heart defects to survive childhood, ${ }^{1}$ there is an omnipresent risk of late circulatory failure, and in adult life, morbidity and mortality are high compared with individuals who have not

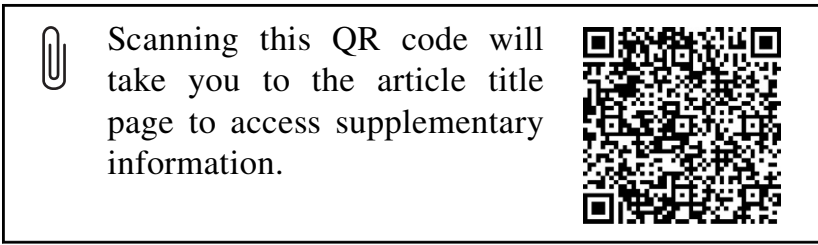



Abbreviations and Acronyms
$\mathrm{CFD}=$ computational fluid dynamics
$\mathrm{CO}=$ cardiac output
$H I=$ hemolysis index
IVC = inferior vena cava
LPA = left pulmonary artery
$\mathrm{PVR}=$ pulmonary vascular resistance
RPA = right pulmonary artery
SVC = superior vena cava
TCPC $=$ total cavopulmonary connection
WSS $=$ wall shear stress

been proposed as a suitable strategy ${ }^{11}$ and have been successful in a few patients. ${ }^{12}$ A proposed self-powered injection jet shunt also has been considered,,$^{13}$ as well as a self-driving turbine. ${ }^{14}$

In the present study, a percutaneously inserted multilumen cannula coupled to a commercially available blood pump is proposed as a potential temporary cavopulmonary assist strategy for adult patients with extracardiac Fontan. The aim is to provide a pressure gain of 2 to $6 \mathrm{~mm} \mathrm{Hg}$ as the primary driving force as a means of improving cardiac output (CO). Computational fluid dynamics (CFD) simulations are used to evaluate performance characteristics of the proposed cannula design. Several flow cases are examined with a range of nominal physiologic flow rates and cavopulmonary-assisted flow rates in an idealized adult TCPC and 2 patient-specific geometries. Blood damage for the most extreme cases is characterized using 2 power-law variants of the hemolysis index $(H I)$ formulation through Lagrangian particle tracking.

Fontan procedure are highly heterogeneous, and the mec anisms of Fontan failure are multifactorial. There is potential for problems at many levels of the circulation, and different modes of Fontan failure often overlap. Despite its many challenges, ${ }^{2}$ heart transplant can be a definitive and successful treatment for Fontan failure, but the indolent nature of decline means many patients are referred late. There are presently no medical devices available to support patients who have undergone the Fontan procedure while they await donor hearts or to rehabilitate a failing Fontan circulation to optimize chances of heart transplant survival. Elevated systemic venous and lymphatic pressures contribute to several modes of Fontan failure and might be mitigated by the addition of an active driver of pulmonary blood flow. Using a cavopulmonary pump to enhance native circulation could also overcome the circulatory impedance of elevated pulmonary vascular resistance (PVR) or pulmonary venous pressures, and other mechanisms of Fontan failure.

There have been several proposals for cavopulmonary assist devices, including the viscous impeller pump, dual-membrane umbrella cannula, ${ }^{5,6}$ and microaxial pumps. $^{7-9}$ These devices work in the Fontan total cavopulmonary connection (TCPC) to decrease unwanted pressure losses induced by collision and mixing of superior vena cava (SVC) and inferior vena cava (IVC) flows, in addition to offsetting effects of any elevated PVR in the pulmonary vascular bed. Data suggest that a cavopulmonary assist device would need to provide 2 to $6 \mathrm{~mm} \mathrm{Hg}$ pressure gain ${ }^{3,10}$ in the central venous part of the Fontan pathway to overcome PVR and pulmonary venous pressures through mechanical means. Devices such as the viscous impeller pump strive to provide longer-term solutions and require surgery to implant, whereas others aim for temporary use as a bridge to transplant and are implanted using minimally invasive approaches. Left ventricular assist devices recently have

\section{MATERIALS AND METHODS \\ Cavopulmonary Assist Device}

The proposed cavopulmonary assist device is a multilumen cannula consisting of 2 extruded discharge lumens and 1 suction lumen located in the center (Figure 1). The discharge lumens have an internal diameter of $4.5 \mathrm{~mm}$ and tapered inner nozzle diameter of $3 \mathrm{~mm}$, whereas the suction lumen has a rectangular cross-section measuring $10 \mathrm{~mm}$ by $3.75 \mathrm{~mm}$. The exterior cross-sectional dimensions of the cannula are $11 \times 15.75 \mathrm{~mm}$, which translates to a $33 \mathrm{~F}$ to $47 \mathrm{~F}$ size (Figure 1). In the proposed strategy, the cannula is inserted through the right internal jugular vein into the TCPC, where 2 guidewires are then used to guide the discharge lumen nozzles toward their respective pulmonary arteries. Blood from the SVC and IVC is siphoned through the suction lumen into an external centrifugal blood pump before being pumped back to the TCPC through the discharge lumens. Each discharge lumen nozzle contains a set of 2 helical protrusions in the interior to induce a slight swirl (Figure 1) to stabilize the flow. The pressurized flow from the pump induces the necessary pressure gradient to overcome downstream PVR. In this study, the pressure gain is defined as the difference between the average left pulmonary artery (LPA) and right pulmonary artery (RPA) pressures and the average IVC, SVC, and left jugular vein pressures.

\section{Idealized and Patient-Specific Total Cavopulmonary Connection Geometries}

An idealized adult Fontan TCPC (Figure E1) was created in SolidWorks (Dassault Systèmes Solid Works Corp, Waltham, Mass) based on typical diameters used in literature. ${ }^{15}$ The idealized TCPC was composed of cylindrical sections with diameters of $22 \mathrm{~mm}$ and $18 \mathrm{~mm}$ for the IVC/SVC and pulmonary arteries, respectively, with $10-\mathrm{mm}$ fillets at the anastomosis intersections. Both the IVC and the SVC were assumed to be $60 \mathrm{~mm}$ in length, and the pulmonary arteries were assumed to be $100 \mathrm{~mm}$ long. Because of symmetry, only half of the TCPC was used for the CFD simulations.

The institutional research ethics board of University Health Network, Toronto approved this study and waived the need for individual patient consent. Cardiac magnetic resonance images of 2 adult patients with extracardiac Fontan undergoing routine clinical imaging were obtained. Patient A was a 21-year-old man with a typical extracardiac TCPC with direct connection of the SVC and a polytetrafluoroethylene (Gore-Tex, WL 


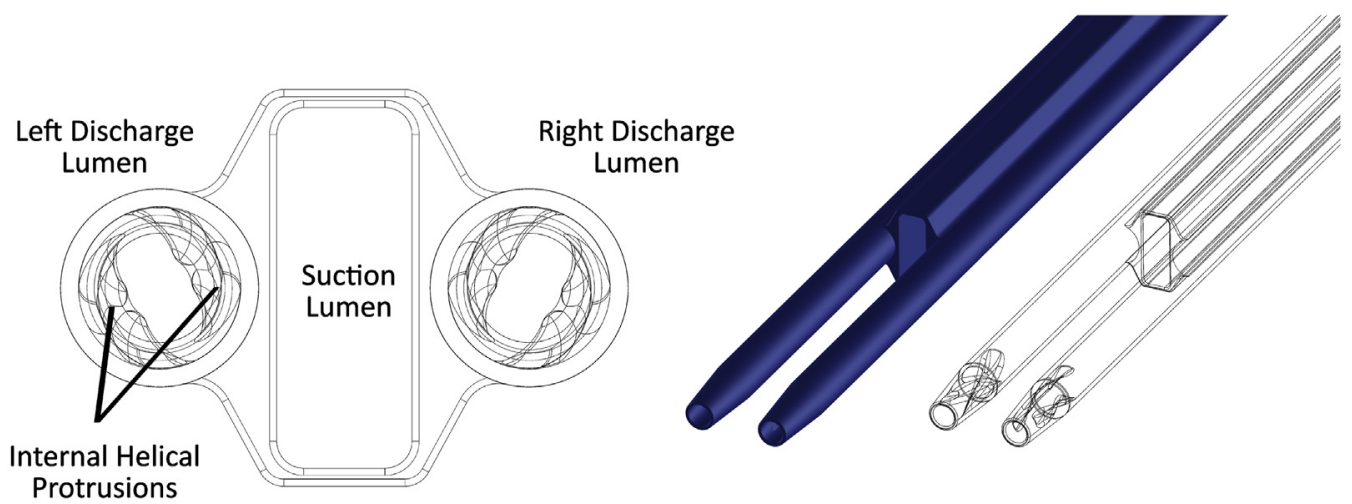

A

B

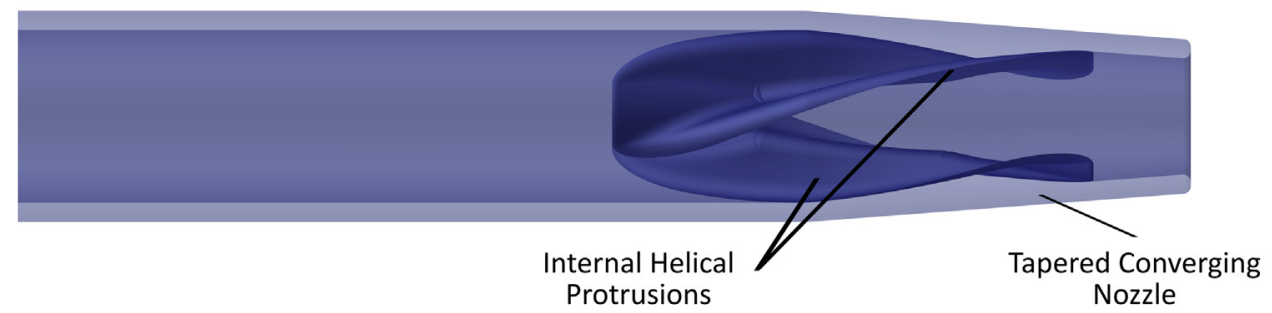

C

FIGURE 1. Cross-sectional (A) and isometric (B) views of the proposed multi-lumen cannula and (C) side view of the helical protrusions.

Gore \& Associates, Flagstaff, Ariz) conduit connection of the IVC to the pulmonary arteries. Patient B, an 18-year-old woman, had a bilateral bidirectional Glenn anastomoses for management of bilateral SVC and a similar Gore-Tex conduit connection of the IVC to the pulmonary arteries. Patient-specific TCPC geometries were segmented with centerline generation and contour lofts using SimVascular. ${ }^{16}$ The geometries were then imported into MeshLab ${ }^{17}$ for surface smoothing and decimation. With the use of SolidWorks, boundary truncations were performed along with circular lofted extensions of the outlet boundaries. Artificial inflation of the SVC branches was performed to simulate elastic expansion of the vessel in the presence of the cannula. Patient A's LPA was mildly constricted and angled posteriorly (Figure E2, $A$ and $B$ ), whereas patient B's LPA bifurcated early into 2 branches in close proximity to the left-sided SVC (Figure E2, $C$ and $D$ ). Also, for patient A, the left jugular vein was included in the model because of its proximity to the TCPC.

\section{Cannula Insertion}

The cannula was inserted virtually in SolidWorks. Cannula positions inside the 3 TCPC cases are shown in Figure 2. In the idealized model, the cannula is located along the SVC centerline with the suction lumen entrance situated $25 \mathrm{~mm}$ above the TCPC center. The discharge lumen was modeled to bend $90^{\circ}$ into the centerline of the pulmonary artery. In the patient-specific models, the suction lumen entrance is situated at a distance away from the anastomosis junction. Care was taken to align the discharge lumens and pulmonary arteries as close to parallel as possible to avoid jet flow from impinging on the vessel walls. In patient $\mathrm{A}$, the left discharge lumen section is modeled longer to follow the sharp LPA bend as shown in Figure 2, B. In Patient B, the left discharge lumen is terminated at a short distance before the LPA bifurcation as shown in Figure 2, $C$. Furthermore, the nozzle is modeled to aim directly at the LPA bifurcation to avoid skewing cannula flow toward one of the LPA branches. Cannula dimensions are kept identical for all TCPC geometries except for the discharge lumen lengths and slight fillet radii differences on the internal helical protrusions.

\section{Computational Fluid Dynamic Simulations}

The commercial finite volume software Fluent v. 17.2-18.1 (ANSYS, Inc, Canonsburg, Pa) was used to conduct steady-state CFD simulations as a first study for the proposed cavopulmonary assist strategy. Blood was assumed to be a Newtonian fluid with a density of $1060 \mathrm{~kg} / \mathrm{m}^{3}$ and a viscosity of $0.0035 \mathrm{~kg} / \mathrm{m} \cdot \mathrm{s}$. Varying flow conditions were simulated to assess the cannula performance with $\mathrm{CO}$ ranging from 1 to $4 \mathrm{~L} / \mathrm{min}$. Different pump flow rates through the cannula were selected equal to $70 \%, 80 \%$, and $90 \%$ of the total CO. In Patient B, the pump flow rates are based on $70 \%, 80 \%$, and $90 \%$ of the IVC and right SVC flow only to avoid flow intake from the distal left SVC.

The transition k-kl- $\omega$ turbulence model with second-order upwind scheme for the continuity equation and first-order upwind scheme for the remaining equations was used for all cases. The first-order upwind scheme for the remaining equations was chosen because of difficulties with convergence for the second-order scheme on patient-specific cases. However, because pressure gain is the primary variable of interest in these simulations, first-order schemes were deemed sufficient on the basis of an approximately $2 \%$ change in pressure gain between first- and second-order schemes for simulations with the idealized TCPC. Residual convergence criteria for all equations was $1 \times 10^{-5}$. Three different mesh sizes for each geometry were used to ensure mesh independence. Final mesh sizes for the idealized and patient-specific cases (patients A and B) were 6.7, 8.9 , and 7.9 million elements, respectively, to ensure that pressure gain errors did not exceed $2.6 \%$.

\section{Boundary Conditions}

Fully developed velocity profiles were prescribed for all inlet boundaries, and uniform pressure was prescribed for all outlet boundaries. Pressures at the LPA and RPA outlets were assumed to be equal. A symmetric boundary was used for the idealized adult TCPC because of symmetry of the geometry. An IVC:SVC flow split of 65:35 was assumed for the idealized TCPC case. ${ }^{18}$ For patient A, $65.0 \%$ of the $\mathrm{CO}$ was prescribed to the IVC, $17.5 \%$ to the SVC, and $17.5 \%$ to the left jugular vein. For patient 


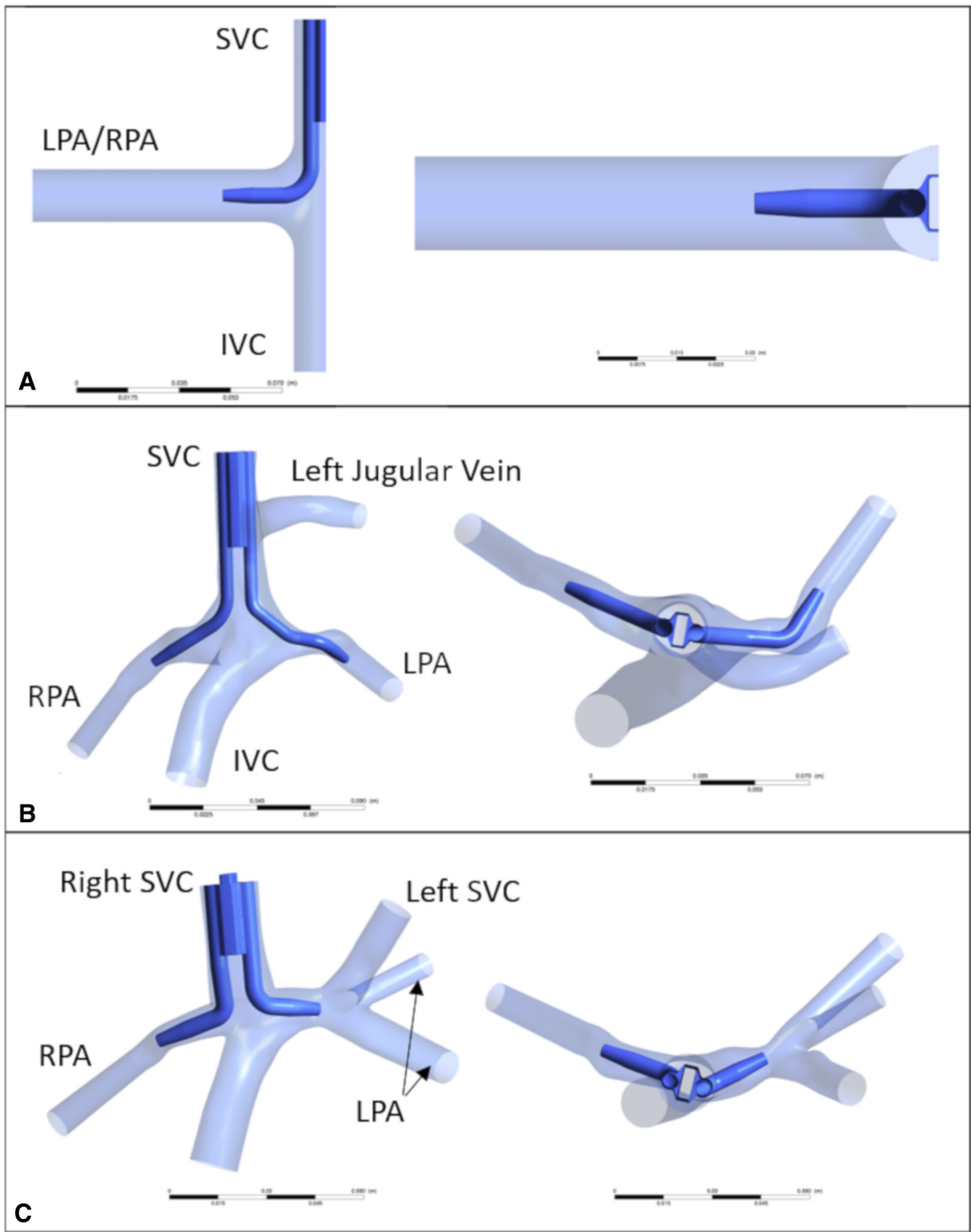

FIGURE 2. Cannula inserted inside the TCPC for (A) the idealized geometry, (B) patient A, and (C) patient B. SVC, Superior vena cava; $L P A$, left pulmonary artery; $R P A$, right pulmonary artery; $I V C$, Inferior vena cava.

B, $60.6 \%$ of the CO was prescribed to the IVC, $19.0 \%$ to the right SVC, and $20.4 \%$ to the left SVC based on data from the magnetic resonance imaging report. For all cases, the pump flow rate at the suction lumen outlet boundary was enforced on the pressure outlet. Equal flow splits of the pump flow were assigned to each discharge lumen. All wall boundaries were set as rigid walls. A summary of the inlet boundary flow rates as a percentage of patient $\mathrm{CO}$ is given in Table E1.

\section{Hemolysis Index}

Blood cell damage is a common concern in biomedical devices, especially in regions with high shear stresses or long residence times. ${ }^{19-21} \mathrm{HI}$ was used as a measure of hemoglobin damage based on particle histories in the flow field. In the symmetric idealized TCPC case, 300 massless particles were injected at each inlet boundary (IVC, SVC, and 1 cannula inlet) for a total of 900 tracked particles. For patient A, 200 massless particles were injected at each inlet boundary (IVC, SVC, left jugular vein or left SVC, and 2 cannula inlets) for a total of 1000 tracked particles. Injection locations at each inlet boundary were first chosen in a pseudorandom distribution such that locations were not unnecessarily close to boundary walls and avoided areas with low velocity magnitudes. This was done using the boundary face mesh nodes as the selection set with filtering to prevent numerical tracking error in the Lagrangian 


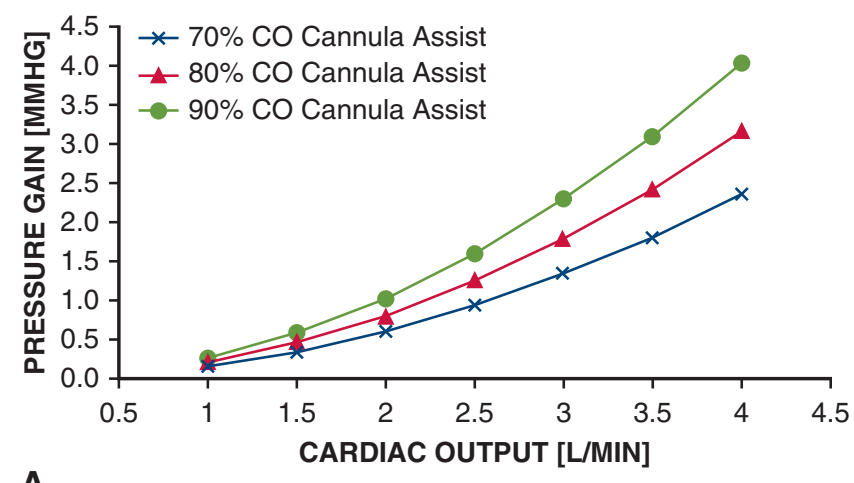

A
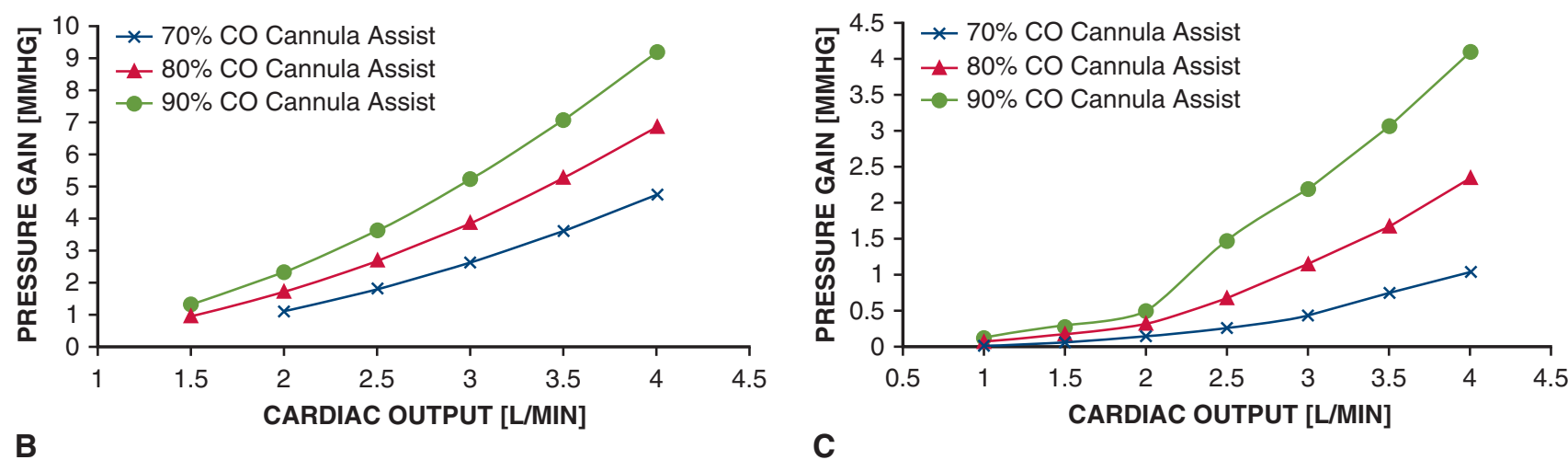

$\mathrm{B}$

FIGURE 3. Pressure gains as a function of $\mathrm{CO}$ and cannula assist rate curves for (A) the idealized geometry, (B) patient A, and (C) patient $\mathrm{B}$. CO, Cardiac output.

discrete phase model in the Fluent solver. The same injection points were then used for all flow cases for a single geometry to maintain consistency. $H I$ was calculated from the particle trajectory histories based on the following power-law

$$
H I=\frac{\Delta H b}{H b}=C \tau_{s}^{\alpha} t_{e x p}^{\beta}
$$

where $\alpha=1.991, \beta=0.765$, and $C=1.8 \times 10^{-5}$ based on Heuser and Opitz, ${ }^{22} \tau_{S}$ is the scalar shear stress, and $t_{\exp }$ is residence time. Two variants of the power law ${ }^{23,24}$ were used to calculate the $H I$

$$
\begin{aligned}
& H I_{1}=\sum_{\text {inlet }}^{\text {outlet }} \beta C t_{\text {exp }}^{\beta-1} \tau_{s}^{\alpha} \Delta t_{\text {exp }}, \\
& H I_{2}=C\left[\sum_{\text {inlet }}^{\text {outlet }} \Delta t_{\text {exp }} \tau_{s}^{\alpha / \beta}\right]^{\beta} .
\end{aligned}
$$

The shear stress ${ }^{25,26}$ in the equations 2 and 3 was calculated as

$\tau_{s}=\frac{1}{\sqrt{3}}\left[\tau_{x x}^{2}+\tau_{y y}^{2}+\tau_{z z}^{2}+3\left(\tau_{x y}^{2}+\tau_{y z}^{2}+\tau_{x z}^{2}\right)-\left(\tau_{x x} \tau_{y y}+\tau_{y y} \tau_{z z}+\tau_{x x} \tau_{z z}\right)\right]^{1 / 2}$.

The $2 \mathrm{HI}$ variants and particle history analysis were conducted using a custom MATLAB (MathWorks, Natick, Mass) script, which was validated against a benchmark case by Hariharan and colleagues. ${ }^{23}$ Hemolysis contributions of each particle were weighted for each outlet boundary and flow-averaged using

$$
H I_{\text {outlet }, i, j}=\frac{1}{Q_{j}} \int_{A_{j}} H I_{i, k} \cdot u_{k} d A_{j},
$$

where $I=1,2, k$ is the index of each particle exiting outlet $j, Q_{j}$ is the volumetric flow, $A_{j}$ is the cross-sectional outlet area, and $u_{k}$ is the corresponding exit velocity magnitude. The overall $H I$ of the TCPC domain was calculated using the following expression for the flow-weighted $\mathrm{HI}$ averages of each outlet:

$$
H I_{T C P S C, i}=\frac{\sum\left[Q_{j} \cdot\left(\int_{A} H I_{i, k} \cdot u_{k} d A\right)_{j}\right]}{Q_{\text {total }}} .
$$

\section{RESULTS \\ Pressure Gains}

Pressure gains as a function of $\mathrm{CO}$ and cannula assist rate are shown in Figure 3. Positive pressure gains were achieved for all flow cases with maximum pressure gains occurring at the highest $\mathrm{CO}$ and cannula assist flow rates. For the idealized and patient $\mathrm{B}$ cases, up to $4 \mathrm{~mm} \mathrm{Hg}$ of pressure increase was attained, whereas more than $9 \mathrm{~mm}$ $\mathrm{Hg}$ was achieved in patient $\mathrm{A}$. The pressure gain curves for patient $\mathrm{A}$ and the idealized TCPC show comparable behavior with proportional pressure gain increases between 

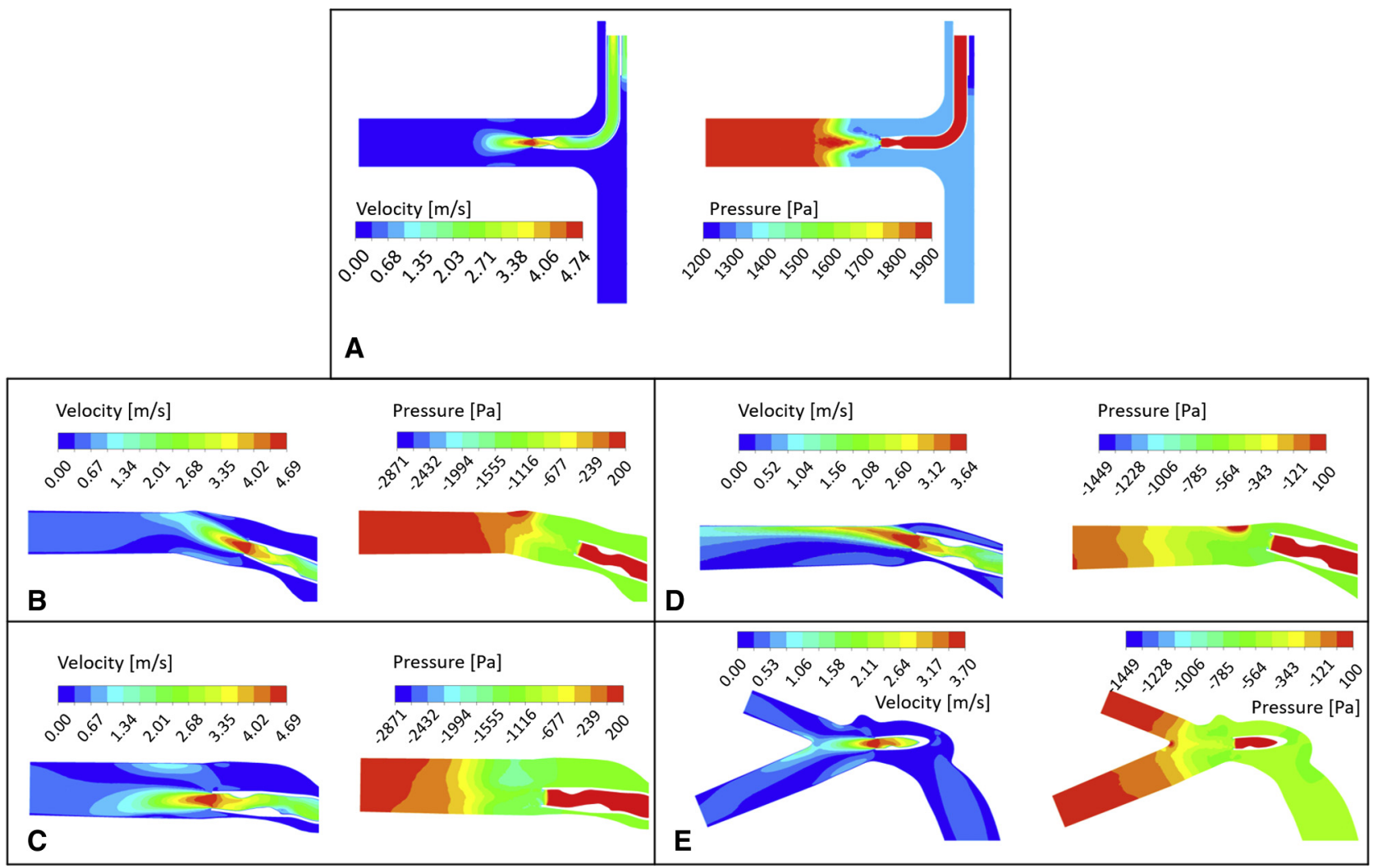

FIGURE 4. Contours for $4 \mathrm{~L} / \mathrm{min} \mathrm{CO}$ with $90 \% \mathrm{CO}$ pump flow in (A) the idealized geometry, (B) patient A RPA, (C) patient A LPA, (D) patient B RPA, and (E) patient B LPA.

different pump flow rates. However, patient B shows a dramatic increase in pressure gain starting at $2.5 \mathrm{~L} / \mathrm{min} \mathrm{CO}$.

\section{Flow Fields}

Velocity and pressure contours for $4 \mathrm{~L} / \mathrm{min} \mathrm{CO}$ and $90 \%$ cannula assist are shown in Figure 4 for all 3 TCPC cases. In the idealized case, symmetric flow structures including vortices near the cannula nozzle can be observed in the velocity contours (Figures 4, A, and E3), whereas the pressure contours illustrate the increased pressure gradient downstream of the cannula nozzle flow. The region of low pressure near the TCPC center and suction lumen is artificially separated by the interaction of cannula nozzle flow with the slower surrounding flow. Likewise, Figures 4, $B$ and $C$, and E4 show velocity contours in the RPA and LPA for patient A with asymmetric vortices. In the RPA side, the nozzle was misaligned and jet flow impinged on the top vessel wall, while the nozzle in the LPA side was positioned nearly parallel to the vessel centerlines. In both pulmonary arteries, high pressure regions were created downstream of the nozzles. Velocity contours (Figures 4, $D$ and $E$, and E5) for patient B also show formation of vortices near the cannula nozzles. Two vortices are present between the LPA birfucation and the nozzle entrance with the one closer to the larger LPA branch being greater in size. Figure 5 shows pathlines colored by velocity magnitude for all 3 TCPC geometries. The majority of blood flow from the IVC is directed into the central suction lumen with the remaining flow going into the RPA and LPA. In the SVC, almost all the flow is siphoned through the suction lumen.

\section{Hemolysis}

The total flow-weighted hemolysis indices, $H I_{T C P C, 1}$ and $H_{T P C P, 2}$, were calculated for the idealized TCPC geometry and are shown in Figure 6. Both hemolysis indices show increased damage with higher $\mathrm{CO}$ and pump flow rates, as expected. Estimates for $H I_{T C P C, 2}$ were consistently higher than $H I_{T C P C, 1}$ for the same flow cases with a maximum $H I_{T C P C}=1.95 \times 10^{-5}$. Both flow-weighted $H I$ show a slight increase starting at $\mathrm{CO}=3 \mathrm{~L} / \mathrm{min}$, as shown in Figure 6. Hemolysis analysis for patient A showed greatest damage in the discharge lumens (Figure E6).

\section{Wall Shear Stress}

Contour plots of wall shear stress (WSS) (Figure 7, A) on the RPA and LPA for patient A show localized areas of high WSS from jet flow impinging on the vessel walls. In the RPA, the nozzle was aimed at an angle toward the upper vessel wall which resulted in WSS up to $55 \mathrm{~Pa}$. In the 


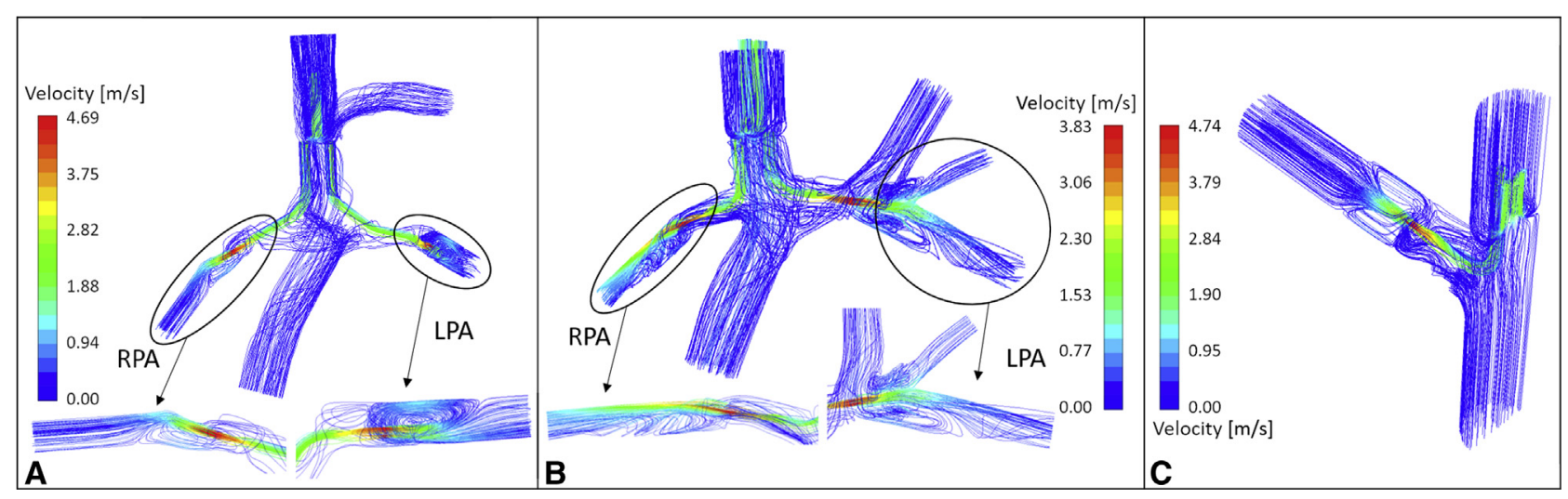

FIGURE 5. Velocity pathlines for $4 \mathrm{~L} / \mathrm{min} \mathrm{CO}$ and $90 \% \mathrm{CO}$ pump flow for (A) patient $\mathrm{A}$, (B) patient $\mathrm{B}$, and (C) the idealized geometry. RPA, Right pulmonary artery; $L P A$, left pulmonary artery.

LPA, where the nozzle was positioned in a near-parallel alignment, WSS up to $34 \mathrm{~Pa}$ occurred at the vessel wall near the nozzle. WSS plots for the LPA bifurcation (Figure $7, B$ ) show small regions with WSS exceeding $130 \mathrm{~Pa}$ where the left cannula nozzle is aimed directly at the junction wall. Small areas of the cannula suction lumen had WSS exceeding $400 \mathrm{~Pa}$ and discharge nozzle close to $400 \mathrm{~Pa}$ as shown in Figure 7, $C$ and $D$.

\section{DISCUSSION}

Pressure gain is commonly used in developing cavopulmonary assist strategies as a temporary or long-term solution for patients with failing Fontan circulations. $^{3}$ Although not directly correlated with changes in central venous pressure (CVP) or $\mathrm{CO}$, it is a forcing term that drives an increase in blood flow through the pulmonary vascular bed. Changes in CVP and CO require fully coupled multiscale CFD simulation or animal testing to be determined. In a multiscale simulation, $\mathrm{CO}$ pulsatility, downstream PVR severity, and end-diastolic function will dictate how effective the cannula-pump is in increasing $\mathrm{CO}$, which is the primary goal. At present, the cannula-pump is not geared toward any particular Fontan failure mode but rather as a generic mechanical circulatory support.

CFD results show pressure gains of up to $4 \mathrm{~mm} \mathrm{Hg}$ at $4 \mathrm{~L} / \mathrm{min} \mathrm{CO}$ in an idealized adult TCPC geometry with an $18-\mathrm{mm}$ diameter pulmonary artery. In patient-specific cases, pressure gain up to $9.2 \mathrm{~mm} \mathrm{Hg}$ was achieved in patient $\mathrm{A}$ and $4 \mathrm{~mm} \mathrm{Hg}$ for patient $\mathrm{B}$. At lower $\mathrm{CO}$ flow rates, the pressure gains in all 3 TCPC cases were substantially lower and highly dependent on the $\mathrm{CO}$ and pump assist flow rates. These pressure gains are not expected to be high enough to damage the pulmonary vascular bed. The pump pressure head requirement (Table E2) is sufficient as the maximum pressure differential needed is less than $95 \mathrm{~mm} \mathrm{Hg}$ excluding pressure losses in tubing sections not modeled in the simulations. Pressure difference measured at a point $5 \mathrm{~mm}$ outside of the cannula suction lumens was a maximum of $9.9 \mathrm{~mm} \mathrm{Hg}$ from the pulmonary arteries and should not cause vessel collapse in a typical elevated failing Fontan pathway. Velocity contours and flow field pathlines showed vortices near the

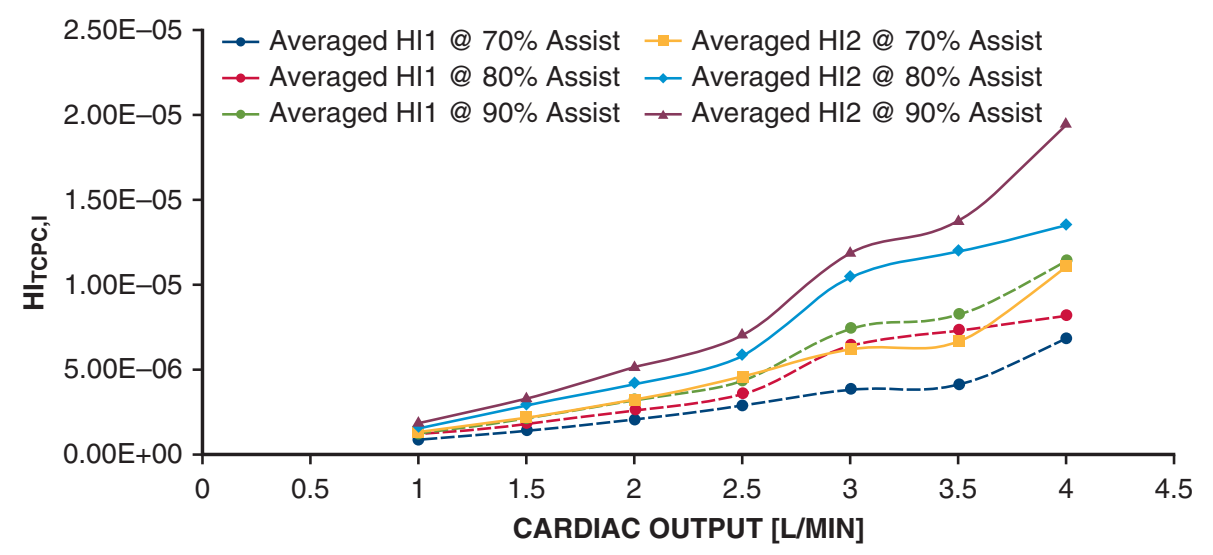

FIGURE 6. Hemolysis indices for the idealized geometry. HI, Hemolysis index; $T C P C$, total cavopulmonary connection. 


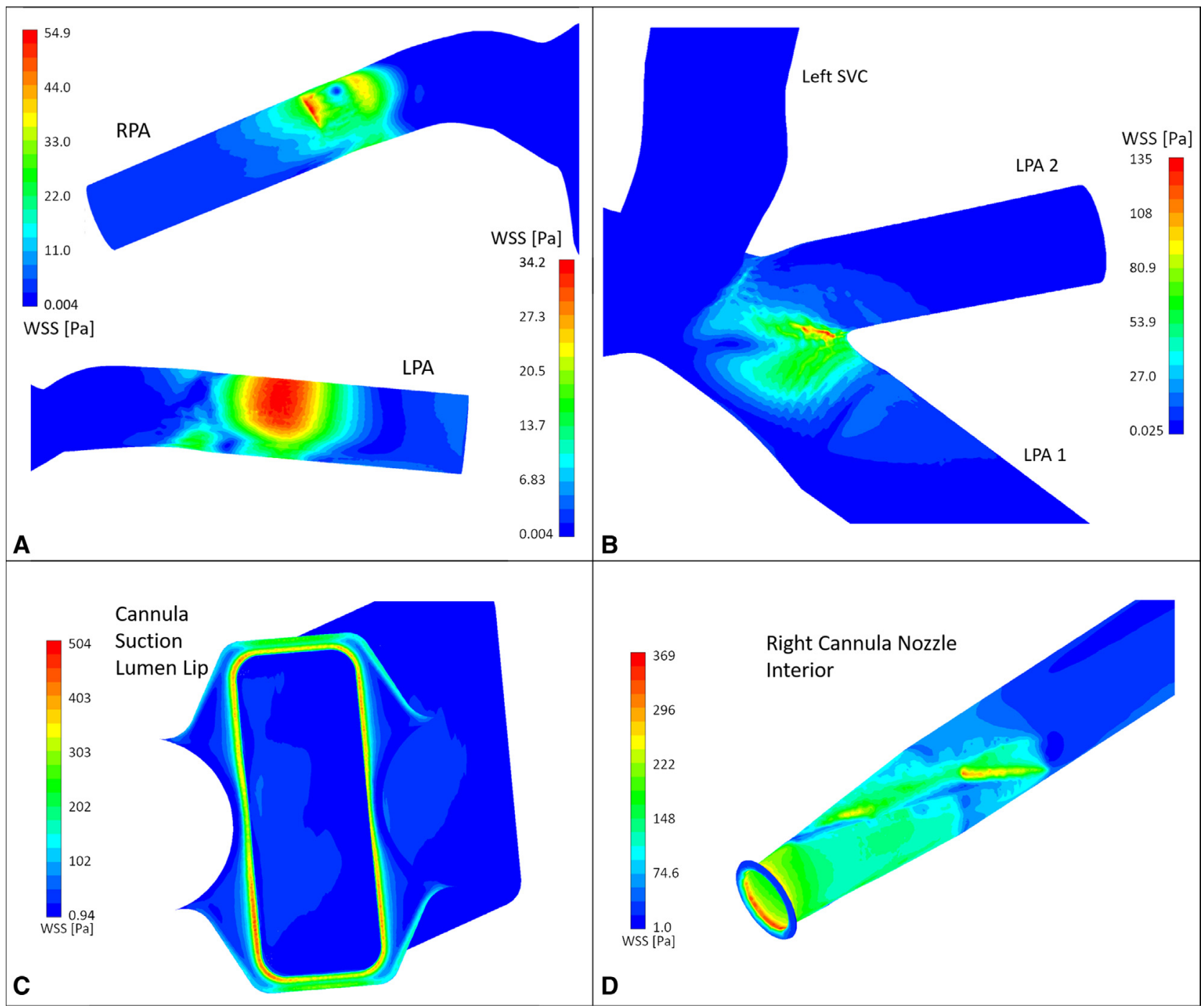

FIGURE 7. WSS contours for $4 \mathrm{~L} / \mathrm{min} \mathrm{CO}$ at $90 \% \mathrm{CO}$ pump flow for (A) patient A RPA and LPA, (B) patient B LPA, (C) cannula suction lumen, and (D) cannula discharge nozzle. RPA, Right pulmonary artery; WSS, wall shear stress; $L P A$, left pulmonary artery; $S V C$, superior vena cava.

cannula nozzles due to mixing of high velocity flow. Depending on the cannula nozzle position and alignment with respect to the vessel centerline, localized areas in the pulmonary arteries experienced elevated WSS. Flowweighted hemolysis analysis of tracked particles in the idealized TCPC showed $H I$ estimates of 1.14 to $1.95 \times 10^{-5}$ for the most extreme flow case using the 2 power-law variants $H_{I}$ and $H I_{2}$, respectively. This result shows that hemoglobin damage in the red blood cells is less than a $2 \%$ threshold used in literature ${ }^{7}$ and is not expected to be a significant concern in the TCPC region. Lower physiologic flow rate cases yielded lower estimates of $H I$ as expected.

The pressure gain is highly dependent on pump flow intake with substantial decrease in performance at lower COs compared with other cavopulmonary assist devices with characteristics similar to traditional pump pressure curves. ${ }^{3,7}$ This performance behavior is a consequence of not physically separating high and low-pressure zones or using driven impellers to directly induce the pressure gradients. Advantages in this approach are the lack of moving components, less susceptibility to circulation obstruction in the event of pump failure, and minimally invasive insertion method. In our proposed device, the discharge lumens inject pressurized flow into the pulmonary arteries directly to minimize energy loss and prevent flow recirculation back into the suction lumen. Furthermore, left and right discharge lumen lengths can be tailored to patient-specific geometries to maximize cavopulmonary assist. The sizes used may be large for the vessel diameter, but flow obstruction should be partially mitigated because of elasticity of the vessel 
walls combined with a noncircular cannula cross-section and the artificially induced low pressure zone at the TCPC center.

Potential limitations were identified with vortices and elevated WSS downstream of the discharge nozzle and in small areas on the cannula. Further investigation of the effects of TCPC geometry is needed because the bifurcated LPA in patient B may have affected the nonlinear pressure gain behavior compared with the other TCPC models. Sensitivity of suction lumen and discharge nozzle locations were not examined in this study, and future work will be done to refine the TCPC model resolution and include secondary pulmonary vascular branches in the RPA/LPA. During preliminary work, partial flow recirculation from the cannula nozzle back into the pump was noted under certain flow conditions when the cannula nozzle was located too close to the suction lumen entrance. Finally, the dependency of the performance on patient TCPC geometry and pump intake flow may limit the number of patients who can use this strategy.

\section{Study Limitations}

The proposed strategy is still conceptual, and further work will address limitations such as appropriate cannula sizing to patient vessel diameters, cannula position sensitivity, device insertion, and effects of different TCPC anatomies. Multiscale CFD simulations are needed to directly determine changes to CVP and $\mathrm{CO}$ because of pressure gains provided by the cavopulmonary assist. Identifying which Fontan failure mode is most appropriate is also required, because it is currently unclear which types (eg, subaortic ventricular failure, elevated PVR) are most suitable. Changes to ventricular end-diastolic pressure and pulmonary vasculature due to the cannula also need to be better characterized. Experimental work is ongoing to address some of these issues and design refinements, whereas further CFD work incorporating realistic coupled-pump responses is currently in progress.

\section{CONCLUSIONS}

A novel multilumen cannula coupled to an external blood pump was presented as a temporary cavopulmonary assist strategy. Computational simulations show potential for a percutaneously inserted cannula to deliver pressure gain inside the Fontan pathway by siphoning blood through an external blood pump and injected through 2 discharge lumens positioned in the pulmonary arteries. With further design refinement and careful surgical planning, a custom-sized multilumen cannula may provide a viable short-term bridge to transplant option for patients who have undergone the Fontan procedure and are awaiting donor hearts.

\section{Conflict of Interest Statement}

Authors have nothing to disclose with regard to commercial support.

\section{References}

1. Diller G-P, Kempny A, Alonso-Gonzalez R, Swan L, Uebing A, Li W, et al. Survival prospects and circumstances of death in contemporary adult congenital heart disease patients under follow-up at a large tertiary centre. Circulation. 2015; 132:2118-25.

2. Kenny LA, DeRita F, Nassar M, Dark J, Coats L, Hasan A. Transplantation in the single ventricle population. Ann Cardiothorac Surg. 2018;7:152-9.

3. Rodefeld M, Coats B, Fisher T, Giridharan GA, Chen J, Brown JW, et al. Cavopulmonary assist for the univentricular Fontan circulation: von Karman viscous impeller pump (VIP). J Thorac Cardiovasc Surg. 2010;140:529-36.

4. Kerlo AE, Delorme YT, Xu D, Frankel SH, Giridharan GA, Rodefeld MD, et al. Experimental characterization of powered Fontan hemodynamics in an idealized total cavopulmonary connection model. Exp Fluids. 2013;54:1581.

5. Wang D, Plunkett M, Lynch J, Zhou X, Ballard-Croft C, Zwischenberger J. Wang-zwische double-lumen cannula leads to total cavopulmonary support in a failing Fontan sheep model. Ann Thorac Surg. 2011;91:1956-60.

6. Wang D, Gao G, Plunkett M, Zhao G, Topaz S, Ballard-Croft C, et al. A paired membrane umbrella double-lumen cannula ensures consistent cavopulmonary assistance in a Fontan sheep model. J Thorac Cardiovasc Surg. 2014;148:1041-7.

7. Throckmorton AL, Carr JP, Tahir SA, Tate R, Downs EA, Bhavsar SS, et al. Mechanical cavopulmonary assistance of a patient-specific Fontan physiology: numerical simulations, lumped parameter modeling, and suction experiments. Artif Organs. 2011;35:1036-47.

8. Chopski SG, Fox CS, Riddle ML, McKenna KL, Patel JP, Rozolis JT, et al. Pressure-flow experimental performance of new intravascular blood pump designs for Fontan patients. Artif Organs. 2016;40:233-42.

9. Zhu J, Kato H, Fu YY, Zhao L, Foreman C, Davey L, et al. Cavopulmonary support with a microaxial pump for the failing Fontan physiology. ASAIO J. 2015;61: 49-54.

10. Rodefeld MD, Frankel SH, Giridharan GA. Cavopulmonary assist:(Em) powering the univentricular Fontan circulation. Semin Thorac Cardiovasc Surg Pediatr Card Surg Annu. 2011;14:45-54.

11. Tree M, Trusty P, Slesnick T, Yoganathan A, Deshpande S, Maher K. In vitro examination of the HeartWare CircuLite ventricular assist device in the Fontan connection. ASAIO J. 2017;63:482-9.

12. Imielski B, Niebler R, Kindel S, Woods R. HeartWare ventricular assist device implantation in patients with Fontan physiology. Artif Organs. 2017;41:40-6.

13. Ni MW, Prather RO, Rodriguez G, Quinn R, Divo E, Fogel M, et al. Computational investigation of a self-powered Fontan circulation. Cardiovasc Eng Technol. 2018;9:202-16.

14. Pekkan K, Aka IB, Tutsak E, Ermek E, Balim H, Lazoglu I, et al. In vitro validation of a self-driving aortic-turbine venous-assist device for Fontan patients. $J$ Thorac Cardiovasc Surg. 2018;156:292-301.e7.

15. Delorme Y, Anupindi K, Kerlo AE, Shetty D, Rodefeld M, Chen J, et al. Large eddy simulation of powered Fontan hemodynamics. $J$ Biomech. 2013;46:408-22.

16. Updegrove A, Wilson N, Merkow J, Lan H, Marsden A, Shadden S. SimVascular: an open source pipeline for cardiovascular simulation. Ann Biomed Eng. 2017; 45:525-41.

17. Cignoni P, Callieri M, Corsini M, Dellepiane M, Ganovelli F, Ranzuglia G. MeshLab: an open-source mesh processing tool. In: Eurographics Italian Chapter Conference; 2008.

18. Cavalcanti S, Gnudi G, Masetti P, Ussia G, Marcelletti C. Analysis by mathematical model of haemodynamic data in the failing Fontan circulation. Physiol Meas 2001;22:209-22.

19. Throckmorton AL, Carr JP, Moskowitz WB, Gangemi JJ, Haggerty CM, Yoganathan AP. Uniquely shaped cardiovascular stents enhance the pressure generation of intravascular blood pumps. J Thorac Cardiovasc Surg. 2012;144: 704-9.

20. Giridharan GA, Koenig SC, Kennington J, Sobieski MA, Chen J, Frankel SH, et al. Performance evaluation of a pediatric viscous impeller pump for Fontan cavopulmonary assist. J Thorac Cardiovasc Surg. 2013;145:249-57.

21. Bhamidipati CM, Ailawadi G, Bergin J, Kern JA. Early thrombus in a HeartMate II left ventricular assist device: a potential cause of hemolysis and diagnostic dilemma. J Thorac Cardiovasc Surg. 2010;140:e7-8. 
22. Heuser G, Opitz R. A Couette viscometer for short time shearing of blood. Biorheology. 1980;17:17-24.

23. Hariharan P, D'Souza G, Horner M, Malinauskas R, Myers M. Verification benchmarks to assess the implementation of computational fluid dynamics based hemolysis prediction models. J Biomech Eng. 2015;137: 094501.

24. Taskin ME, Fraser K, Zhang T, Wu C, Griffith B, Wu Z. Evaluation of Eulerian and Lagrangian models for hemolysis estimation. ASAIO J. 2012;58: 363-72.
25. Bludszuweit C. Three-dimensional numerical prediction of stress loading of blood particles in a centrifugal pump. Artif Organs. 1995;19:590-6.

26. Apel J, Paul R, Klaus S, Siess T, Reul H. Assessment of hemolysis related quantities in a microaxial blood pump by computational fluid dynamics. Artif Organs. 2001;25:341-7.

Key Words: computational fluid dynamics, cavopulmonary assist, Fontan circulation, multilumen cannula, hemolysis 


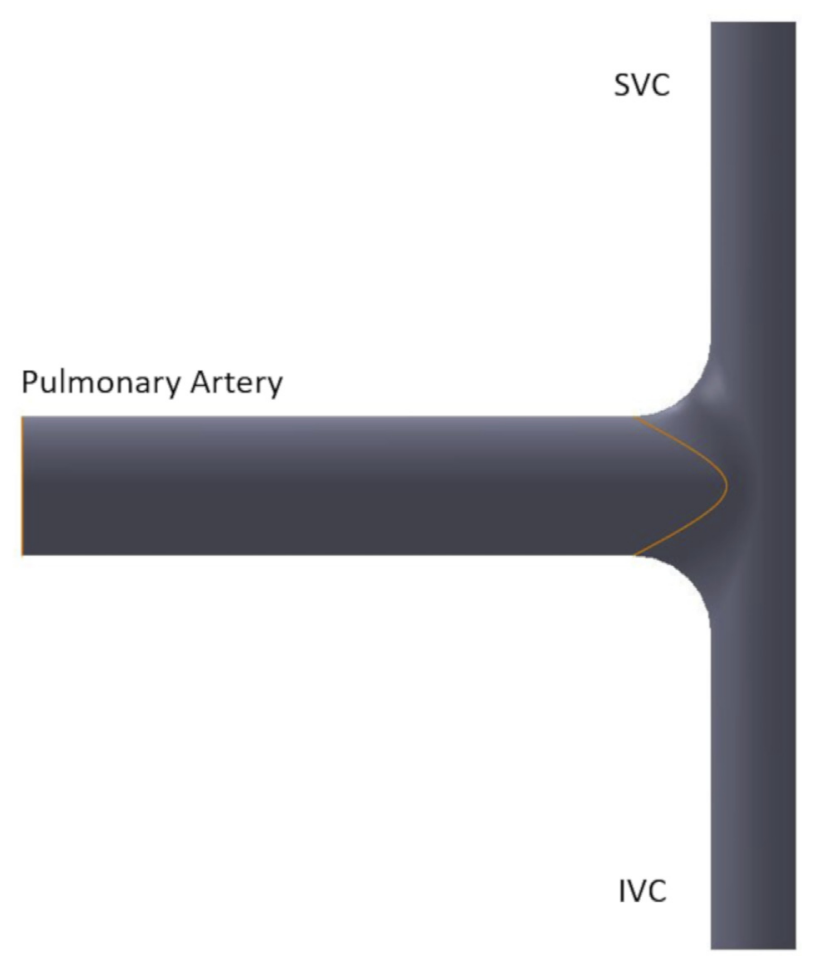

FIGURE E1. Symmetric idealized adult TCPC geometry. SVC, Superior vena cava; $I V C$, inferior vena cava. 

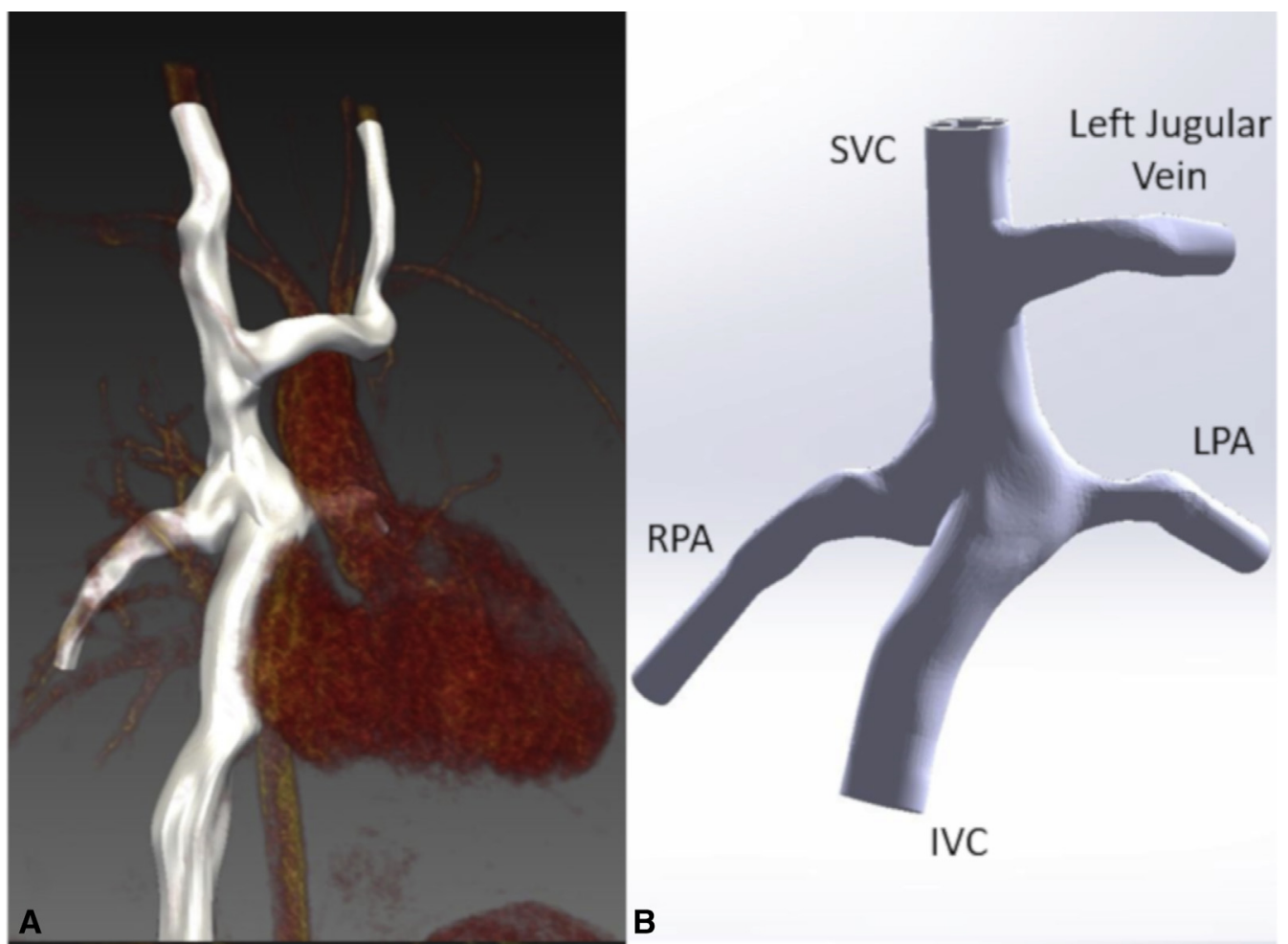

IVC

A

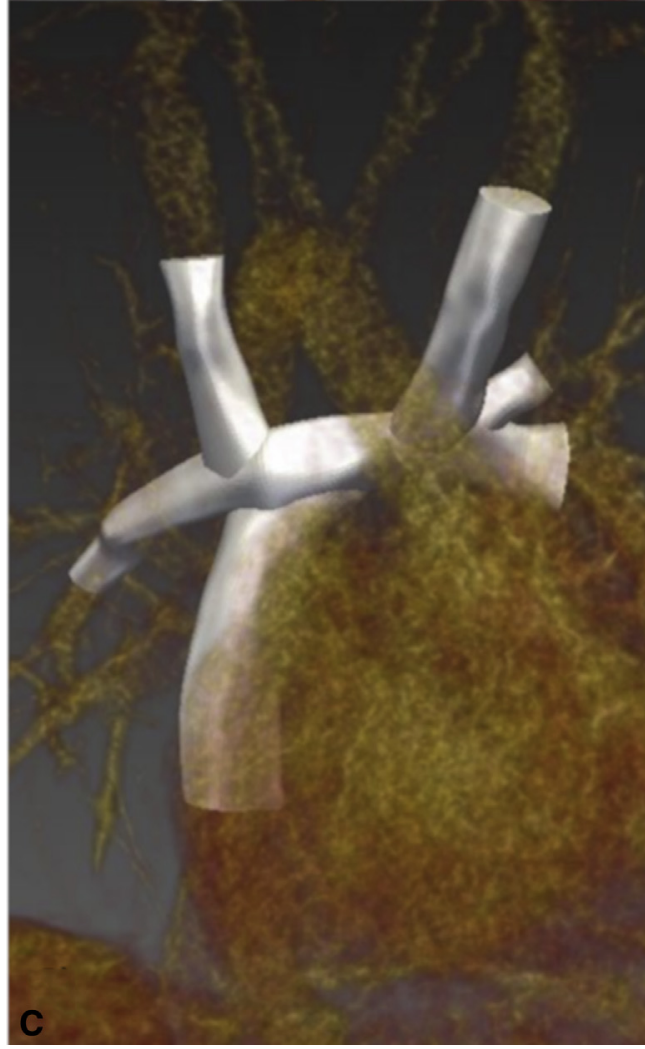

B

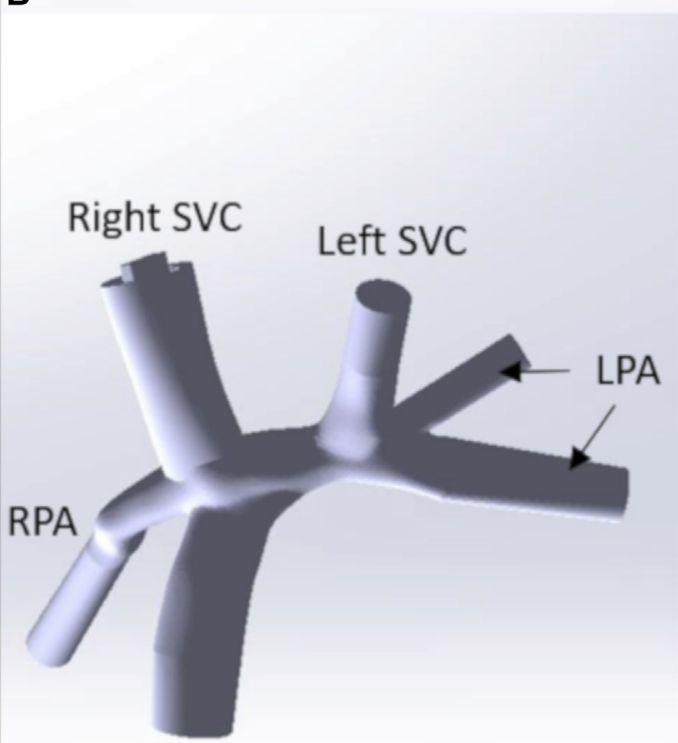

IVC

FIGURE E2. A, Patient A segmentation with MRI rendering. B, Patient A with surface smoothing and boundary extension/truncation. C, Patient B segmentation with MRI rendering. D, Patient B with surface smoothing and boundary extension/truncation. SVC, Superior vena cava; $L P A$, left pulmonary artery; $R P A$, right pulmonary artery; $I V C$, inferior vena cava. 


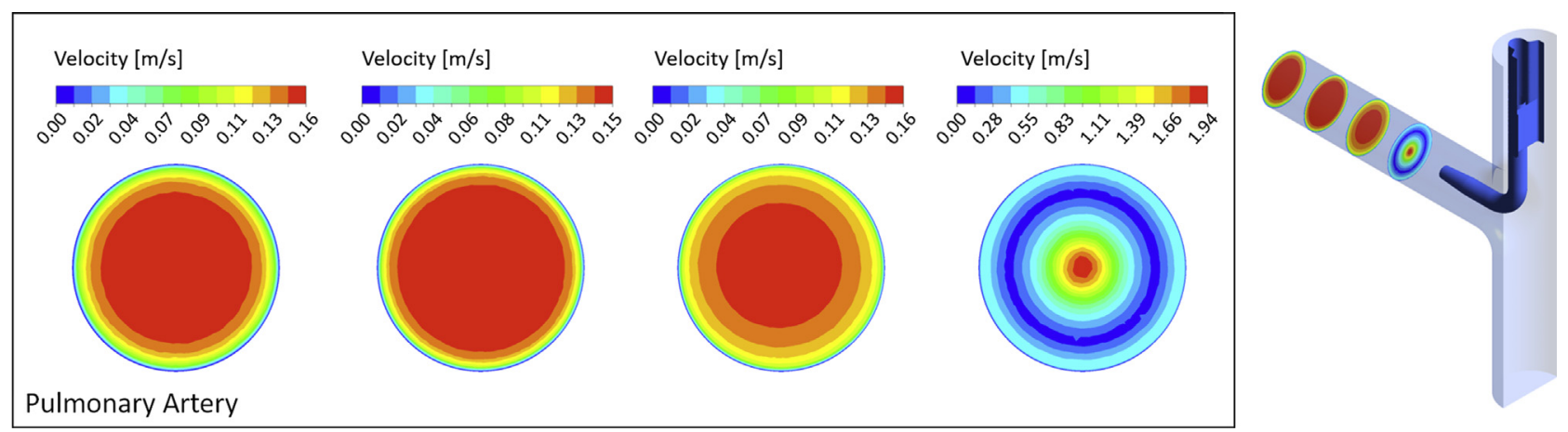

FIGURE E3. Velocity contours for $4 \mathrm{~L} / \mathrm{min} \mathrm{CO}$ with $90 \%$ CO pump flow in the idealized geometry.
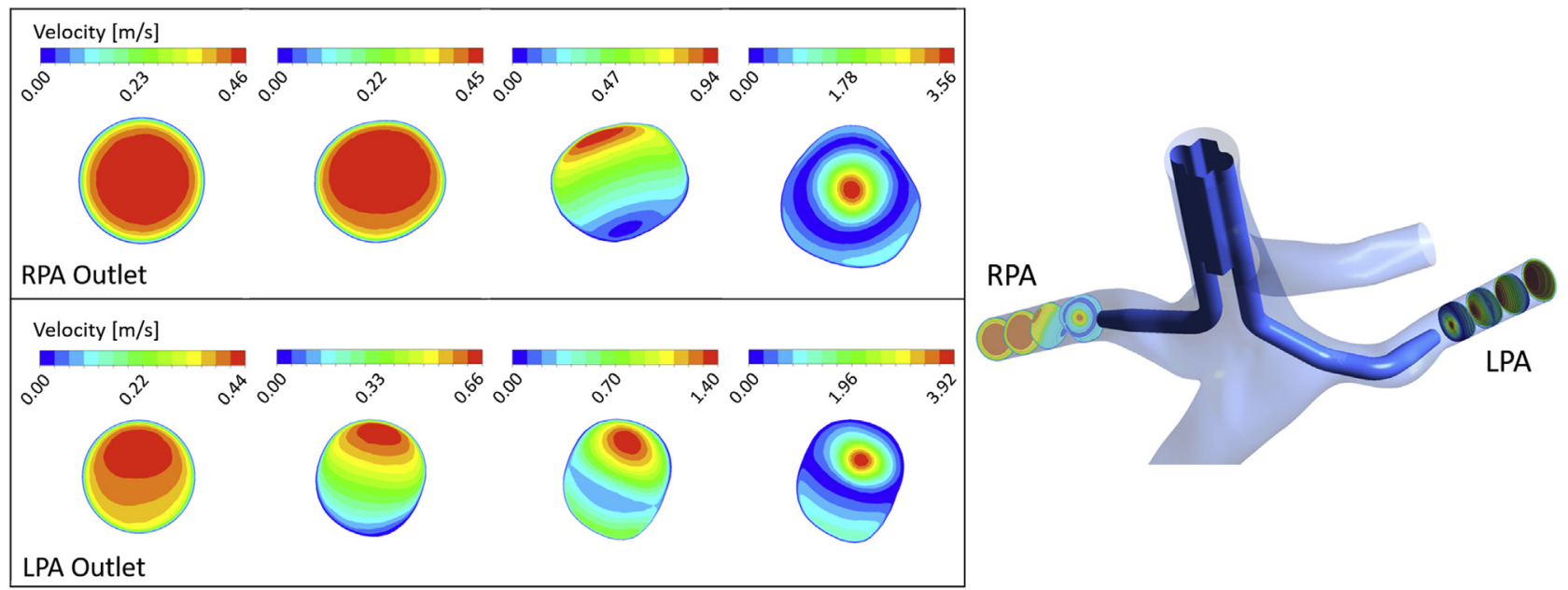

FIGURE E4. Velocity contours for $4 \mathrm{~L} / \mathrm{min} \mathrm{CO}$ with $90 \% \mathrm{CO}$ pump flow for patient A. Top row: RPA contours. Bottom row: LPA contours. RPA, Right pulmonary artery; $L P A$, left pulmonary artery. 

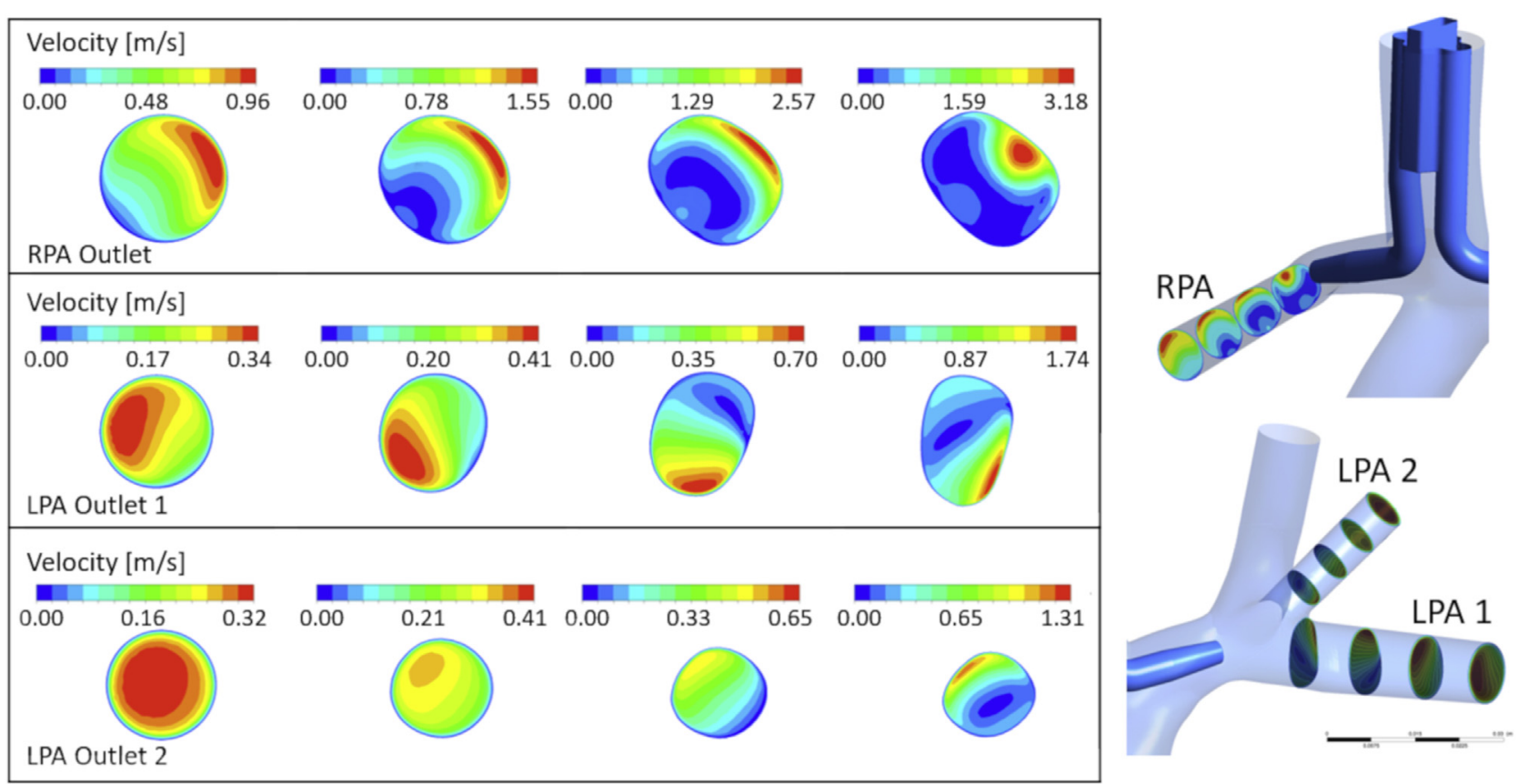

FIGURE E5. Velocity contours for $4 \mathrm{~L} / \mathrm{min} \mathrm{CO}$ with $90 \% \mathrm{CO}$ pump flow for patient B. Top row: RPA contours. Bottom: LPA contours. RPA, Right pulmonary artery; $L P A$, left pulmonary artery.
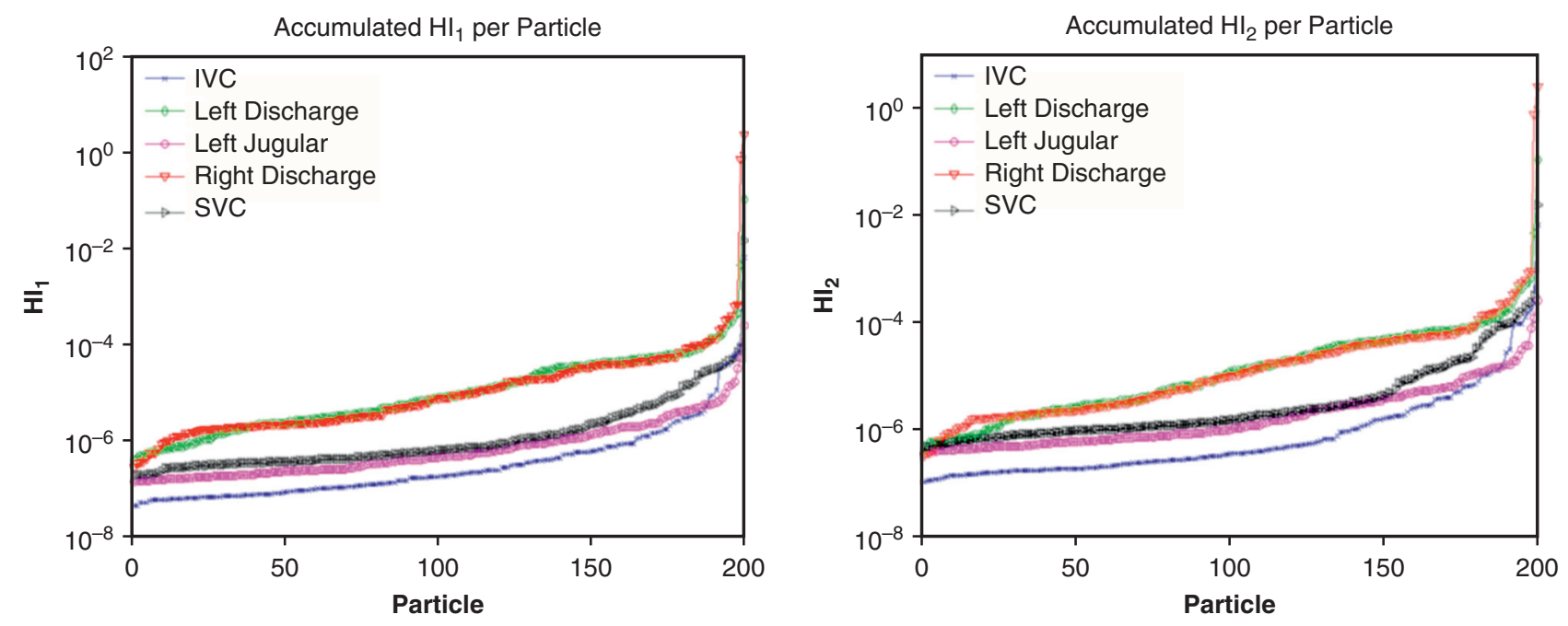

FIGURE E6. Accumulated hemolysis indices by particle $H I_{l}(l e f t)$ and $H I_{2}(r i g h t)$ for patient A with $4 \mathrm{~L} / \mathrm{min} \mathrm{CO}$ and $90 \% \mathrm{CO}$ pump flow. $H I$, Hemolysis index; $I V C$, inferior vena cava; $S V C$, superior vena cava. 
TABLE E1. Inlet boundary flow rates as percentage of cardiac output

\begin{tabular}{lccccc}
\hline \multicolumn{1}{c}{ TCPC case } & $\begin{array}{c}\text { IVC } \\
\text { flow (\%) }\end{array}$ & $\begin{array}{c}\text { SVC } \\
\text { flow (\%) }\end{array}$ & $\begin{array}{c}\text { Left jugular or } \\
\text { left SVC flow (\%) }\end{array}$ & $\begin{array}{c}\text { Cannula (pump) } \\
\text { flow (70 } \%, \mathbf{8 0} \% \mathbf{9 0} \%)\end{array}$ & $\begin{array}{c}\text { Cannula discharge } \\
\text { lumen flow split }\end{array}$ \\
\hline Idealized & 65.0 & 35.0 & - & IVC + SVC & $50: 50$ \\
Patient A (left jugular vein) & 65.0 & 17.5 & 17.5 & IVC + SVC + left jugular & $50: 50$ \\
Patient B (left SVC) & 60.6 & 19.0 & 20.4 & IVC + SVC & $50: 50$ \\
\hline
\end{tabular}

$\overline{T C P C}$, Total cavopulmonary connection; $I V C$, Inferior vena cava; $S V C$, superior vena cava.

TABLE E2. Summary of pump pressure requirements

\begin{tabular}{lcc}
\hline TCPC case & $\begin{array}{c}\text { Maximum } \Delta \mathbf{P} \\
\text { between suction- } \\
\text { discharge } \\
\text { lumens }(\mathbf{m m} \mathbf{H g})\end{array}$ & $\begin{array}{c}\text { Maximum } \Delta \mathbf{P} \text { between } \\
\text { suction lumen entrance- } \\
\text { pulmonary artery } \\
\text { outlet(s) }(\mathbf{m m} \mathbf{H g})\end{array}$ \\
\hline Idealized & 94.8 & -4.6 \\
Patient A & 93.2 & -9.9 \\
Patient B & 60.3 & -4.9 \\
\hline
\end{tabular}

$T C P C$, Total cavopulmonary connection. 